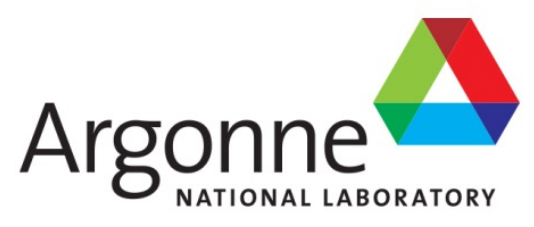

ANL/CSE-13/44

\title{
Processing of Sintered Mo Disks Using Hydrogen Peroxide
}

Chemical Science and Engineering Division 


\begin{abstract}
About Argonne National Laboratory
Argonne is a U.S. Department of Energy laboratory managed by UChicago Argonne, LLC under contract DE-AC02-06CH11357. The Laboratory's main facility is outside Chicago, at 9700 South Cass Avenue, Argonne, Illinois 60439. For information about Argonne and its pioneering science and technology programs, see www.anl.gov.
\end{abstract}

\title{
DOCUMENT AVAILABILITY
}

Online Access: U.S. Department of Energy (DOE) reports produced after 1991 and a growing number of pre-1991 documents are available free via DOE's SciTech Connect (http://www.osti.gov/scitech/)

Reports not in digital format may be purchased by the public from the National Technical Information Service (NTIS):

U.S. Department of Commerce

National Technical Information Service

5301 Shawnee Rd

Alexandra, VA 22312

www.ntis.gov

Phone: (800) 553-NTIS (6847) or (703) 605-6000

Fax: (703) 605-6900

Email: orders@ntis.gov

Reports not in digital format are available to DOE and DOE contractors from the Office of Scientific and Technical Information (OSTI):

U.S. Department of Energy

Office of Scientific and Technical Information

P.O. Box 62

Oak Ridge, TN 37831-0062

www.osti.gov

Phone: (865) 576-8401

Fax: (865) 576-5728

Email: reports@osti.gov

\footnotetext{
Disclaimer

This report was prepared as an account of work sponsored by an agency of the United States Government. Neither the United States Government nor any agency thereof, nor UChicago Argonne, LLC, nor any of their employees or officers, makes any warranty, express or implied, or assumes any legal liability or responsibility for the accuracy, completeness, or usefulness of any information, apparatus, product, or process disclosed, or represents that its use would not infringe privately owned rights. Reference herein to any specific commercial product, process, or service by trade name, trademark, manufacturer, or otherwise, does not necessarily constitute or imply its endorsement, recommendation, or favoring by the United States Government or any agency thereof. The views and opinions of document authors expressed herein do not necessarily state or reflect those of the United States Government or any agency thereof, Argonne National Laboratory, or UChicago Argonne, LLC.
} 


\section{Processing of Sintered Mo Disks Using Hydrogen Peroxide}

by

Peter Tkac ${ }^{1}$, George Vandegrift', Stephen D. Nunn², and James Harvey ${ }^{3}$ ${ }^{1}$ Chemical Science and Engineering Division, Argonne National Laboratory ${ }^{2}$ Oak Ridge National Laboratory

${ }^{3}$ NorthStar Medical Technologies, LLC

prepared for

U.S. Department of Energy, National Nuclear Security Administration, Office of Defense Nuclear Nonproliferation

September 30, 2013 



\section{CONTENTS}

INTRODUCTION

2 SINTERED Mo DISKS.

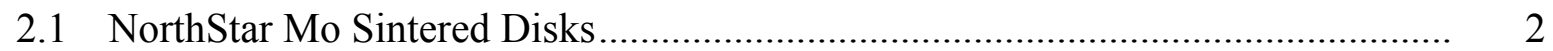

2.2 ORNL Mo Sintered Disks............................................................................. 2

3 DISSOLUTION OF SINTERED Mo DISKS ...................................................... 6

3.1 Dissolution of Northstar Sintered Mo Disks................................................... 6

3.2 Dissolution of ORNL Sintered Mo Disks ........................................................... 9

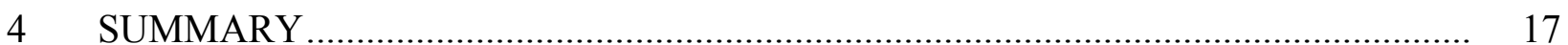

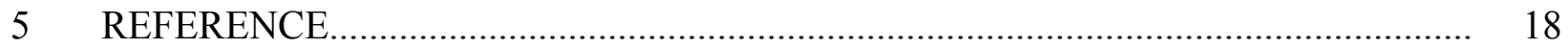

\section{FIGURES}

$1 \quad$ Dependence of Disks' Packing Density on Pressing Conditions.............................. 3

2 Dependence of Disks' Thickness on Pressing Conditions...................................... 3

3 Dependence of Disks' Diameter on Pressing Conditions ...................................... 4

4 Dependence of Disks’ Packing Density on Sinter Conditions.................................... 4

$5 \quad$ Dependence of Disks' Thickness on Sinter Conditions....................................... 5

6 Dependence of Disks' Diameter on Sinter Conditions ........................................ 5

7 Dependence of Dissolution Rates on Pressing Conditions for Disks Sintered

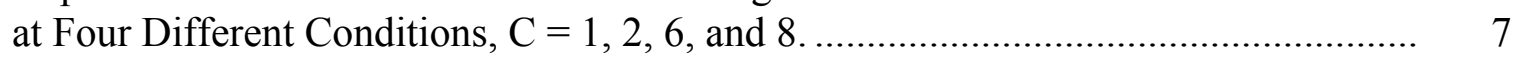

8 Dependence of Dissolution Rates on packing Density for Disks Sintered at

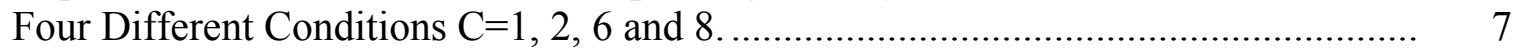

9 Dissolution Rates of Disks Pre-sintered at $A=7$ and Sintered at Different

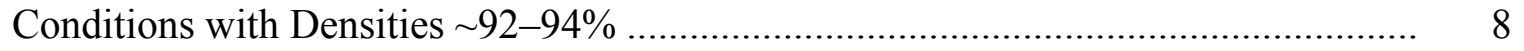

10 Optical Micrographs of Polished Sections of Mo Disks Pre-sintered at A = 7, Pressed at $\mathrm{B}=9$, and Sintered at Four Different Conditions $\mathrm{C}=1,2,6$, and 8 . 


\section{FIGURES (Cont.)}

11 Comparison of Dissolution Rates Versus Packing Density for Non-sintered and Sintered Disks Made of Different Starting Material

12 SEM Images of Two Climax Mo Powders As-Received, and Fracture

Surfaces of As-Pressed and Sintered Disks

13 SEM Images of Fracture Surfaces of Sintered AEE Mo Disks Show the Effect of Sintering Temperatures on the Microstructure

14 Comparison of Dissolution Rates Versus Sintering Temperature for Different Mo powders Pretreated at Different Conditions

15 Dependence of Dissolution Rates of Non-sintered Mo Disks on Packing Density......

\section{TABLES}

$1 \quad$ Characteristics of Sintered Mo Disks and Corresponding Dissolution Rates.............. 10

$2 \quad$ Characteristics of Sintered Mo Disks and Corresponding Dissolution Rates.............. 11

3 Characteristics of Sintered $>99 \%$ Mo-100 Enriched Disks and Corresponding Dissolution Rates 


\section{PROCESSING OF SINTERED Mo DISKS USING HYDROGEN PEROXIDE}

\section{INTRODUCTION}

Dissolution studies of sintered molybdenum (Mo) disks using hydrogen peroxide have been focused on several factors that could potentially affect processing of Mo disks. It was demonstrated (Tkac 2012) that stronger pre-sinter and sinter conditions lead to the lowest dissolution rates. Milder pre-sinter, or no pre-sinter, and very strong sinter conditions usually lead to disks with the highest packing densities and lowest dissolution rates. In contrast, stronger pre-sinter conditions and very mild sinter conditions lead to higher dissolution rates. In this report, we discuss results of dissolution of sintered Mo disks provided by NorthStar Medical Technologies, LLC (NorthStar), and disks prepared at Oak Ridge National Laboratory (ORNL). 


\section{SINTERED Mo DISKS}

Disks were prepared by a commercial vendor for NorthStar (which in turn provided them to Argonne National Laboratory [Argonne]), and by ORNL. Each type is discussed in a separate section below.

\subsection{NORTHSTAR Mo SINTERED DISKS}

Sintered Mo disks were prepared by pressing Mo metal powder sieved through a 400-mesh sieve (particle size $<38 \mu \mathrm{m}$ ) and then sintered to make a disk with specific dimensions. Mo metal powder was prepared by reduction of commercially available $\mathrm{MoO}_{3}$ (Strem Chemicals Inc.). The goal was to study the effects of pressing parameters on the dissolution rate and packing density for disks sintered under four different conditions. While information about the conditions in which the Mo disks were made is not available (proprietary information of the commercial disk manufacturer under contract to NorthStar), there is a relative measure of different conditions during pre-sintering and sintering. The disks are described by a threedigit code $\mathrm{ABC}$ (e.g., "741") where the first digit $(\mathrm{A}=7)$ is the pre-sinter condition, the second digit $(B=4)$ is the pressing variable, and the third digit $(C=1)$ is the sintering condition. Higher numbers equate to stronger conditions (e.g., temperature of sintering or time of sintering, pressure used for pressing). Packing density was calculated from the mass of the disk and physical dimensions of the disk.

All disks were prepared from $A=7$ pre-sintered material and the weight of disks was $\sim 1.07 \mathrm{~g}$. The pressing parameter was in the range of $\mathrm{B}=8-11$; sintering conditions were $\mathrm{C}=1,2,6$, and 8 . The dependence of the disks' packing density, thickness, and diameter on various pressing conditions is shown in Figures 1 through 3. Figures 4 through 6 show the dependence of these three parameters on sintering conditions. As expected, packing densities increase with higher pressing and sintering conditions, thickness decreases with increased pressing, and diameter increases with pressing and decreases with sintering.

\subsection{ORNL Mo SINTERED DISKS}

Sintered Mo disks provided by ORNL were prepared from multiple commercial Mo powders. The disks were pressed in steel dyes without any binder or lubricant added to the powder, and sintered in a tube furnace $\left(\mathrm{Al}_{2} \mathrm{O}_{3}\right)$. During sintering, the disks were placed in an alumina boat with Ar gas flowing until the oxygen level in the exiting gas was less than $100 \mathrm{ppm}$. Then the gas was switched to $\mathrm{Ar} / 4 \% \mathrm{H}_{2}$, and the furnace was heated at $10^{\circ} \mathrm{C} / \mathrm{min}$ to the desired sintering temperature. The furnace was usually held at the peak temperature for 1 hour and then cooled to room temperature. The densities of the sintered disks vary with temperature, starting density (green, or as-pressed density), and powder characteristics. The densities of the sintered disks were determined using Archimedes' method and may differ from the value obtained from the physical dimensions of the disk. The Archimedes method gives a much more accurate value for small objects. 

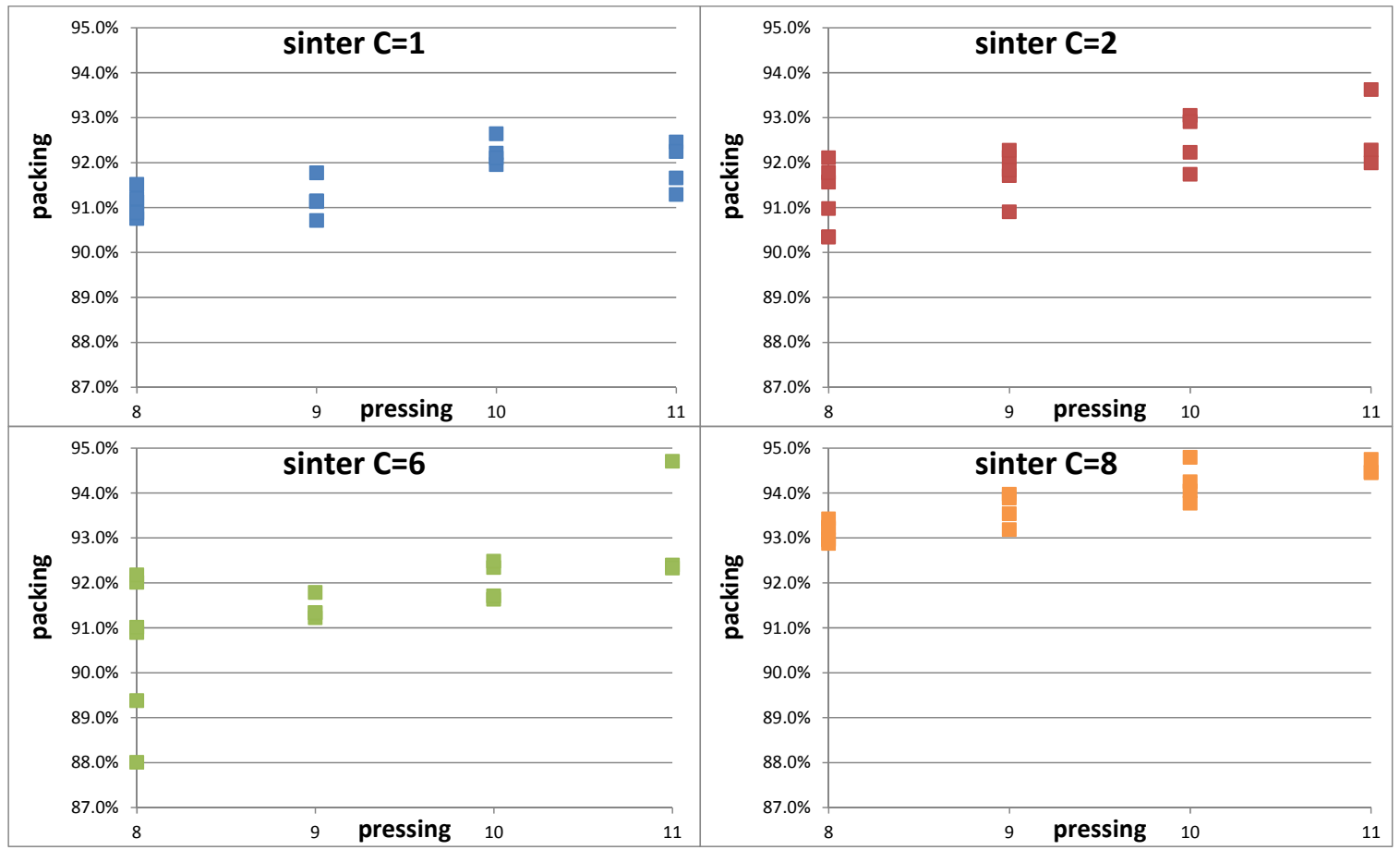

FIGURE 1 Dependence of Disks' Packing Density on Pressing Conditions
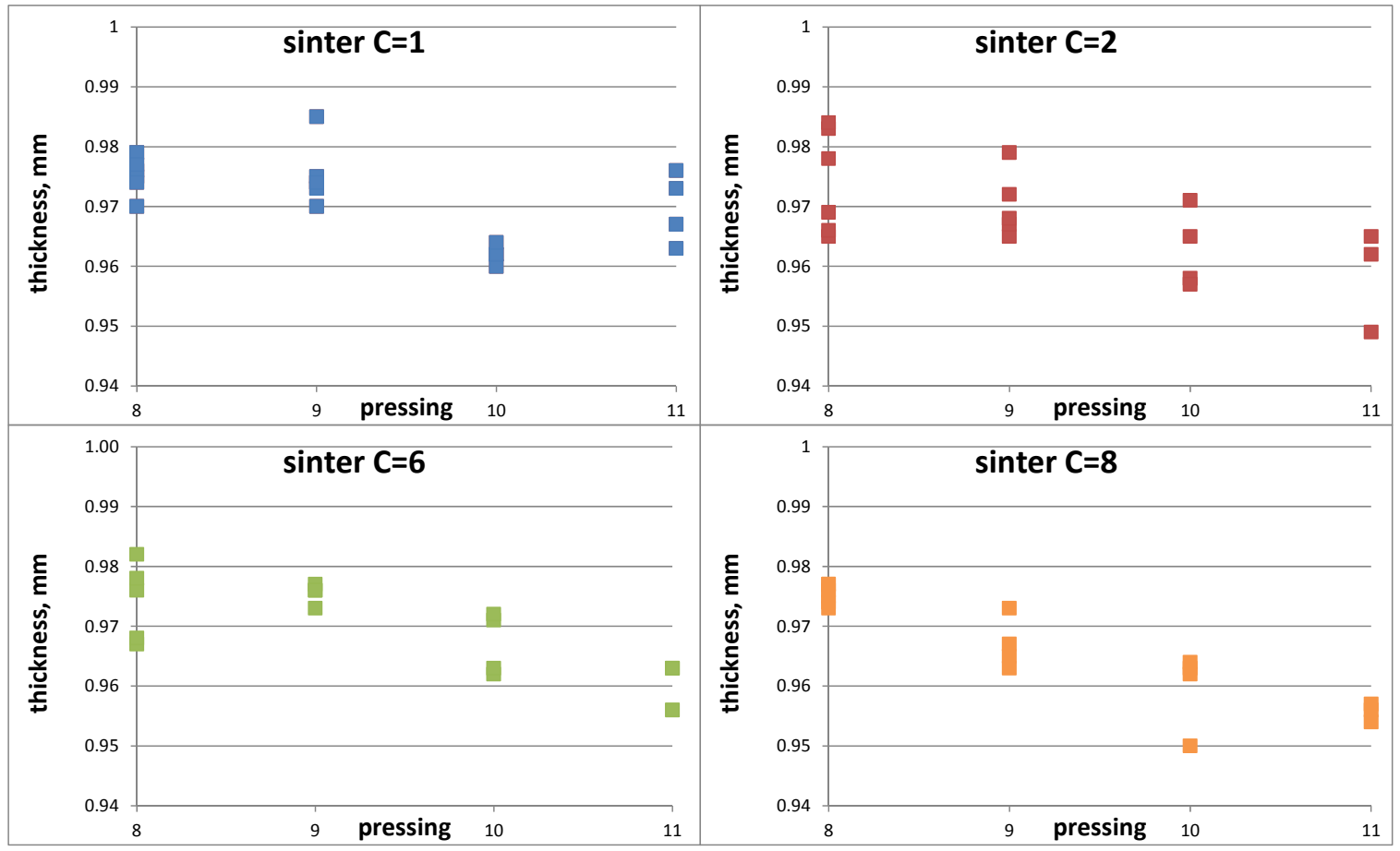

FIGURE 2 Dependence of Disks' Thickness on Pressing Conditions 


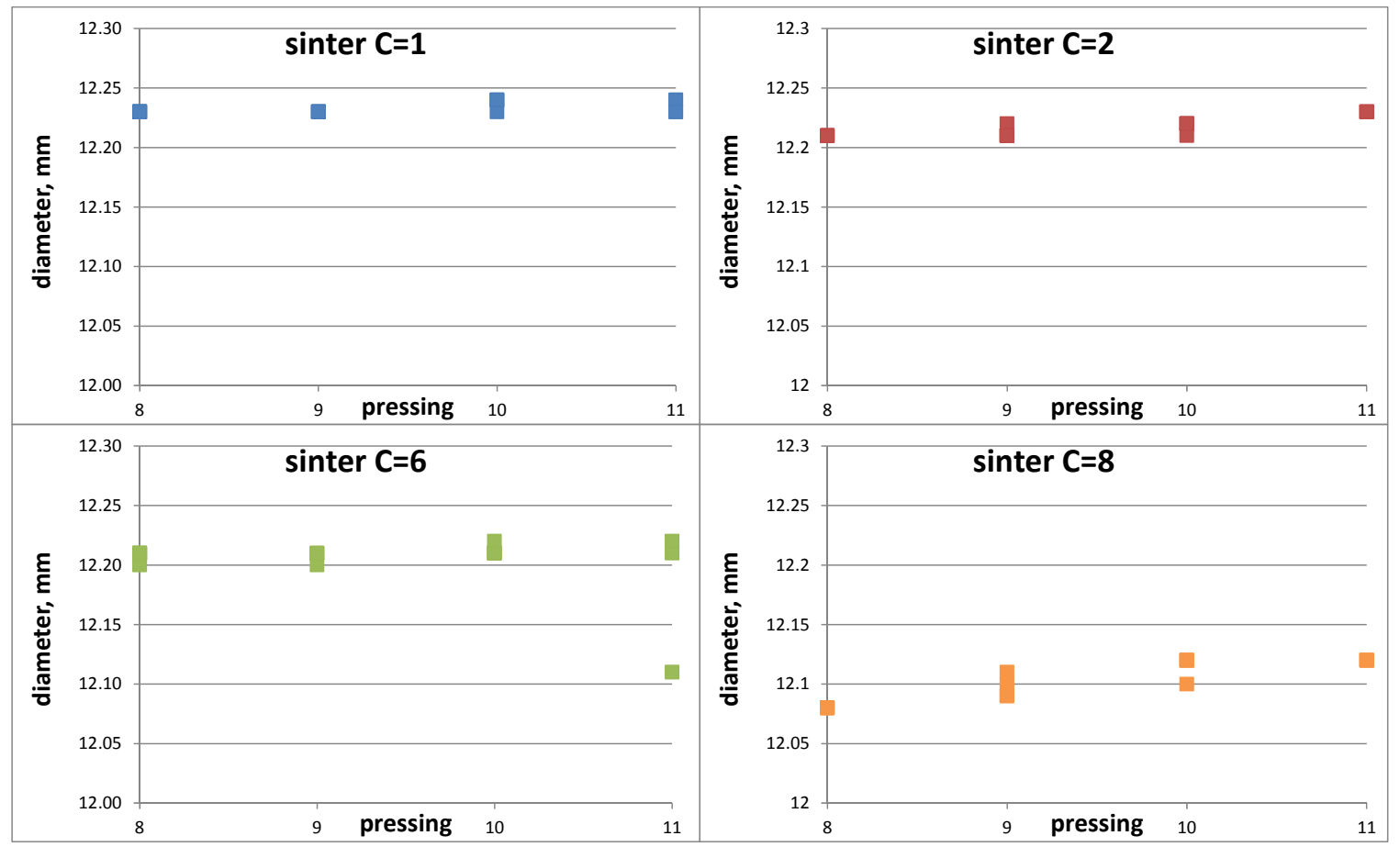

FIGURE 3 Dependence of Disks' Diameter on Pressing Conditions

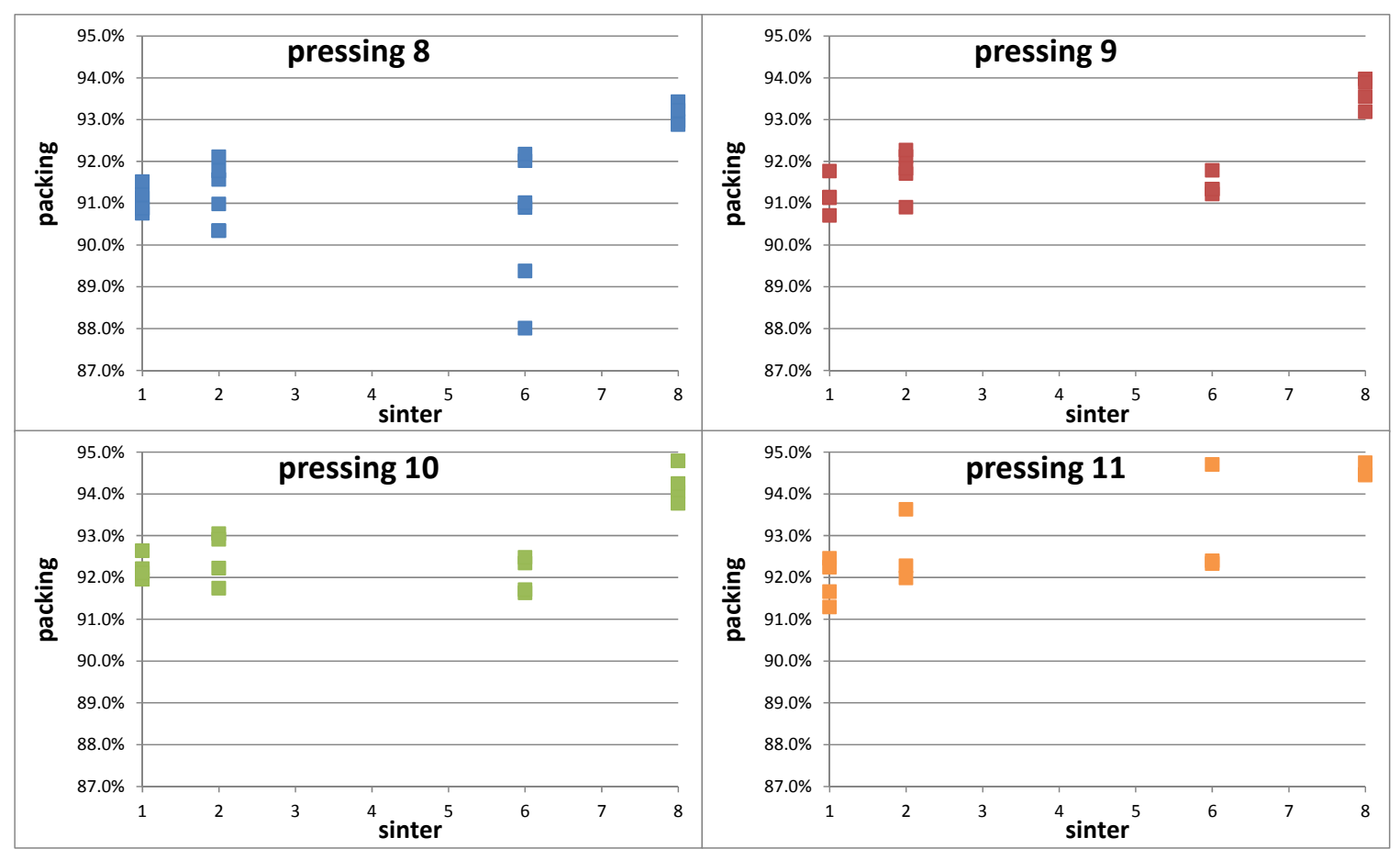

FIGURE 4 Dependence of Disks' Packing Density on Sinter Conditions 

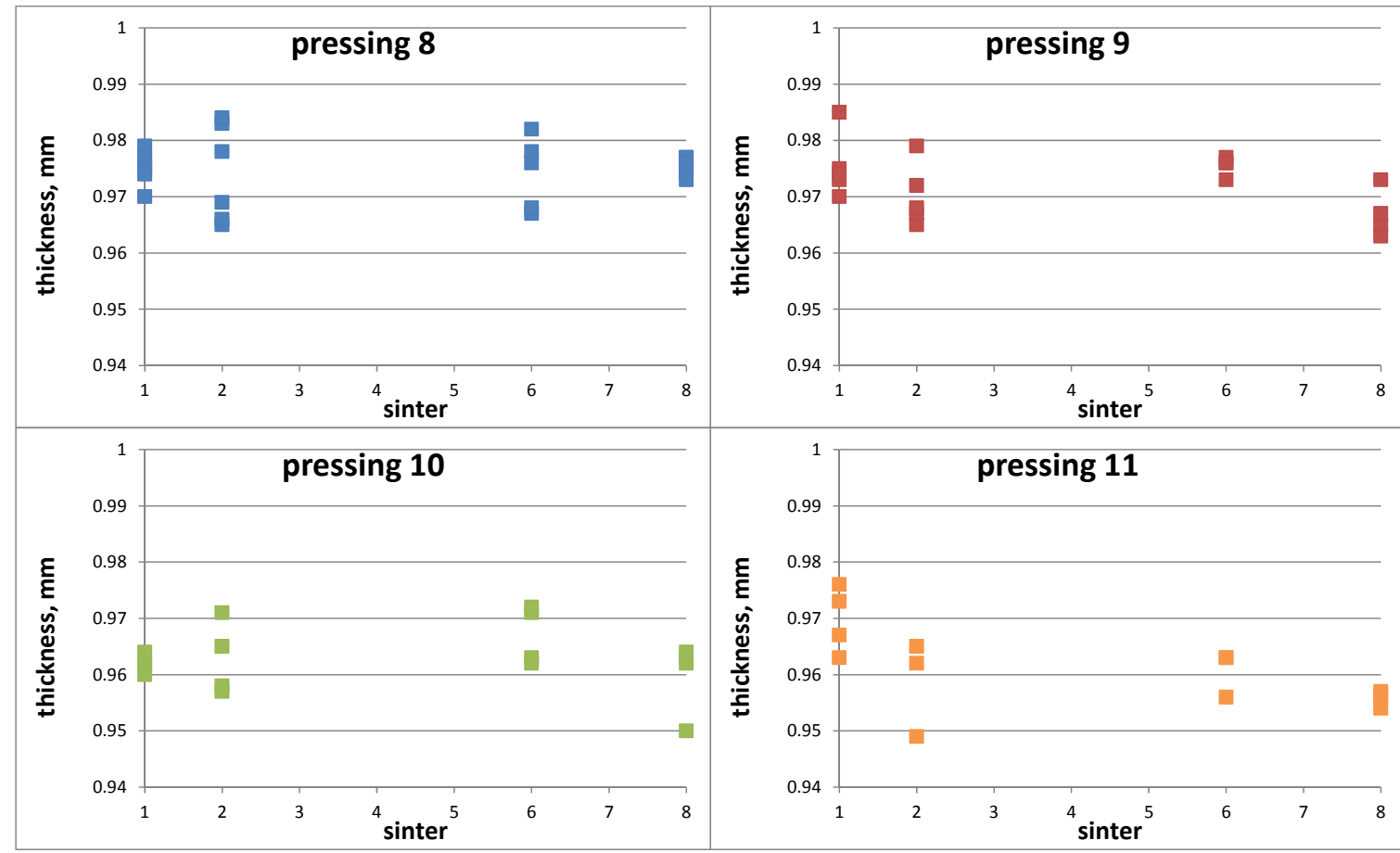

\section{FIGURE 5 Dependence of Disks' Thickness on Sinter Conditions}
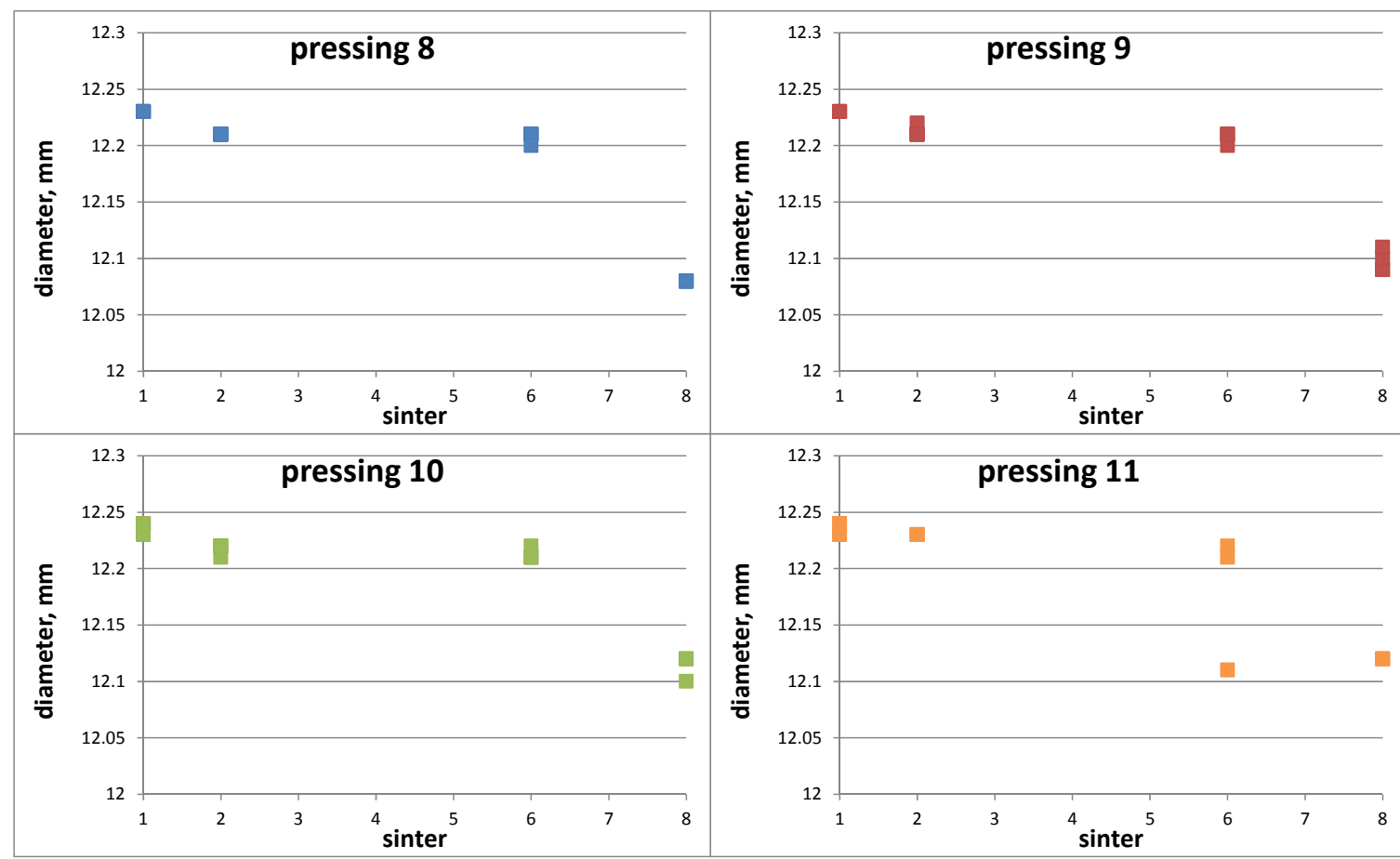

FIGURE 6 Dependence of Disks' Diameter on Sinter Conditions 


\section{DISSOLUTION OF SINTERED Mo DISKS}

Dissolution studies were performed in a glass beaker, usually using $40 \mathrm{~mL}$ of $30 \%$ hydrogen peroxide heated to $70^{\circ} \mathrm{C}$. In some cases, different volumes of hydrogen peroxide were used in order to achieve complete dissolution. Shortly after adding the disks into hydrogen peroxide a yellow solution forms, indicating the presence of Mo-peroxo species, and the temperature increases rapidly to about $95-100^{\circ} \mathrm{C}$ within several seconds. There is a significant increase in dissolution rate once the $\mathrm{H}_{2} \mathrm{O}_{2}$ reaches $\sim 85-90^{\circ} \mathrm{C}$. This is most likely due to the catalytic destruction of peroxide and formation of oxygen in the solution, which reacts aggressively with the Mo. The reason for pre-heating $\mathrm{H}_{2} \mathrm{O}_{2}$ solution to $70^{\circ} \mathrm{C}$ is to test the properties of the disks and distinguish among disks with "good" and "bad" dissolution properties. "Good" dissolving disks reach $\sim 90^{\circ} \mathrm{C}$ within $10-20$ seconds (if starting with $70^{\circ} \mathrm{C}_{2} \mathrm{O}_{2}$ ). If the Mo disks do not dissolve very well, the temperature of the $\mathrm{H}_{2} \mathrm{O}_{2}$ solution starts to decrease and the dissolution progresses very slowly without additional heating. These disks usually do not dissolve even after several hours. For the dissolution studies, if the temperature of hydrogen peroxide after adding the Mo disk did not increase above $70^{\circ} \mathrm{C}$ within 1-2 minutes, the solution was heated to $95-100^{\circ} \mathrm{C}$ in order to promote dissolution.

\subsection{DISSOLUTION OF NORTHSTAR SINTERED Mo DISKS}

All disks were pre-sintered at $\mathrm{A}=7$. Figure 7 shows the dissolution rates of Mo disks sintered at $\mathrm{C}=1,2,6$, and 8 conditions versus pressing conditions in the range of $\mathrm{B}=8-11$. In general, increased pressing 'does not have a significant impact (and density, see Figure 1) for disks sintered at $\mathrm{C}=1$ and $\mathrm{C}=2$ (7B1 and 7B2). Very good dissolution rates of $\sim 0.6 \mathrm{~g} / \mathrm{min}$ for $7 \mathrm{~B} 1$ and $\sim 0.4 \mathrm{~g} / \mathrm{min}$ for $7 \mathrm{~B} 2$ disks were observed for all pressing conditions. On the other hand, disks sintered at $\mathrm{C}=6$ and 8 dissolved significantly slower, and these disks showed a noticeable trend of decreased dissolution rates with pressing and density (Figure 7). It should be noted that all disks sintered at $\mathrm{C}=8$ needed to be heated in order to achieve complete dissolution. The solution was heated to $\sim 95^{\circ} \mathrm{C}$.

Disks with up to $\sim 95 \%$ packing density can be easily prepared; however, data in Figure 8 show that the dissolution properties strongly depend on pre-sinter and sinter conditions. By increasing pressing conditions, even lightly sintered disks with $\mathrm{C}=1$ and 2 had packing densities in the range of $\sim 90-94 \%$ but had significantly higher dissolution rates compared to disks sintered at stronger conditions $(\mathrm{C}=6$ and 8$)$.

Figure 9 compares the dissolution rates for disks with packing densities in the range of $92-94 \%$ and sintered under four different sets of conditions. It shows the benefit of using lighter sinter conditions to achieve very good dissolution rates for disks with densities $>90 \%$.

Optical micrographs of disks sintered under four different conditions (Figure 10) show significant changes in disk microstructure due to different sintering conditions. It should be noted that most of the apparent porosity for disks sintered at $\mathrm{C}=1$ is due to removal of poorly bonded particles during the grinding and polishing operations. The disks sintered under stronger 


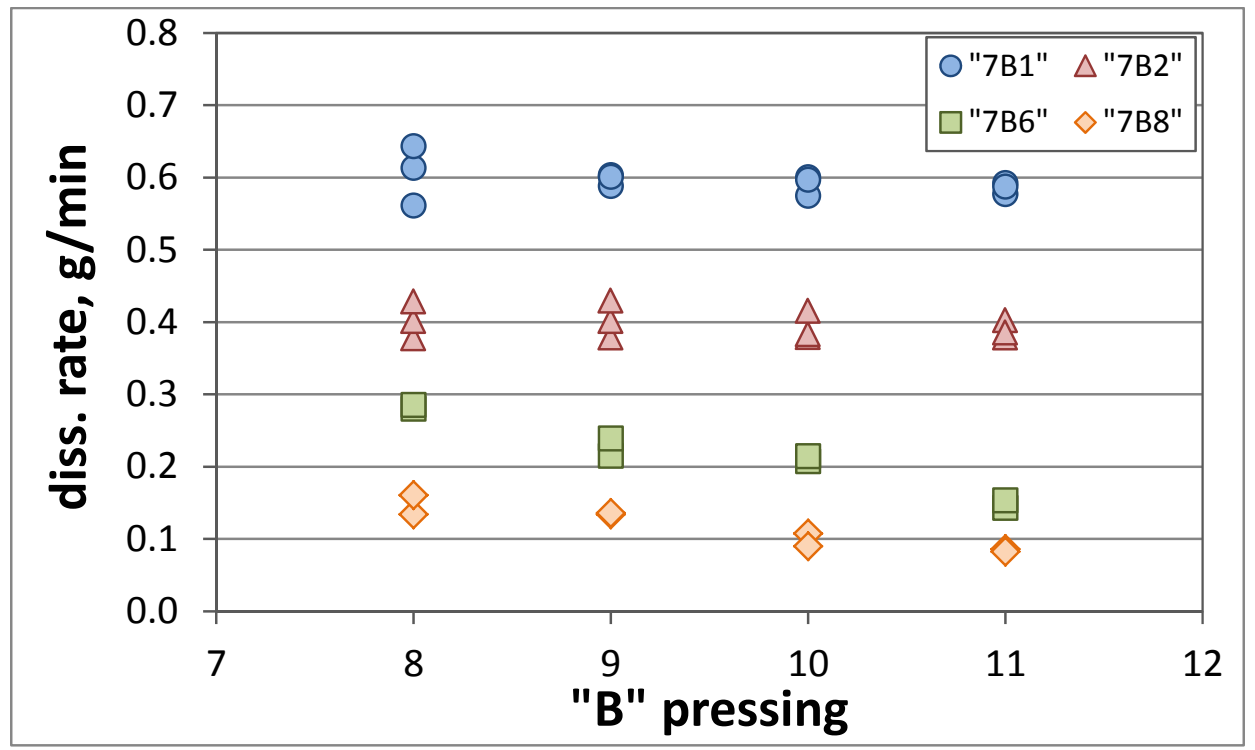

FIGURE 7 Dependence of Dissolution Rates on Pressing Conditions for Disks Sintered at Four Different Conditions, C = 1, 2, 6, and 8.

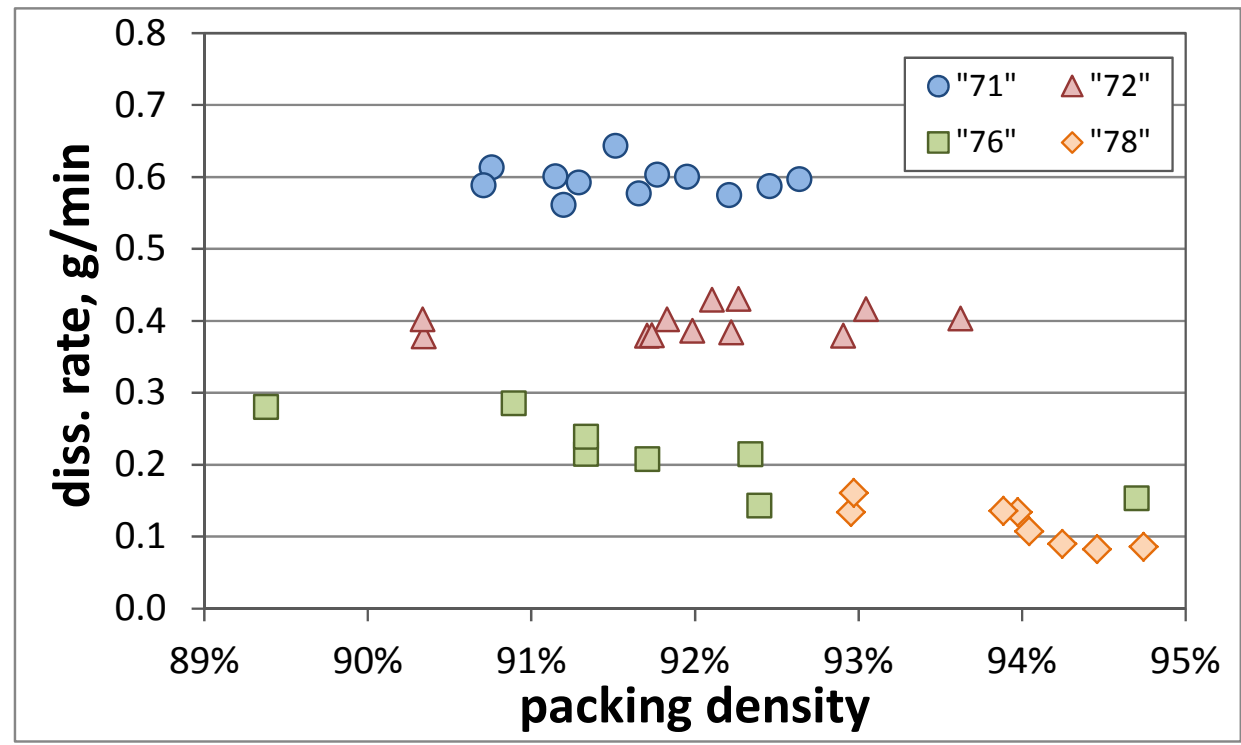

FIGURE 8 Dependence of Dissolution Rates on packing Density for Disks Sintered at Four Different Conditions C=1, 2, 6 and 8. 


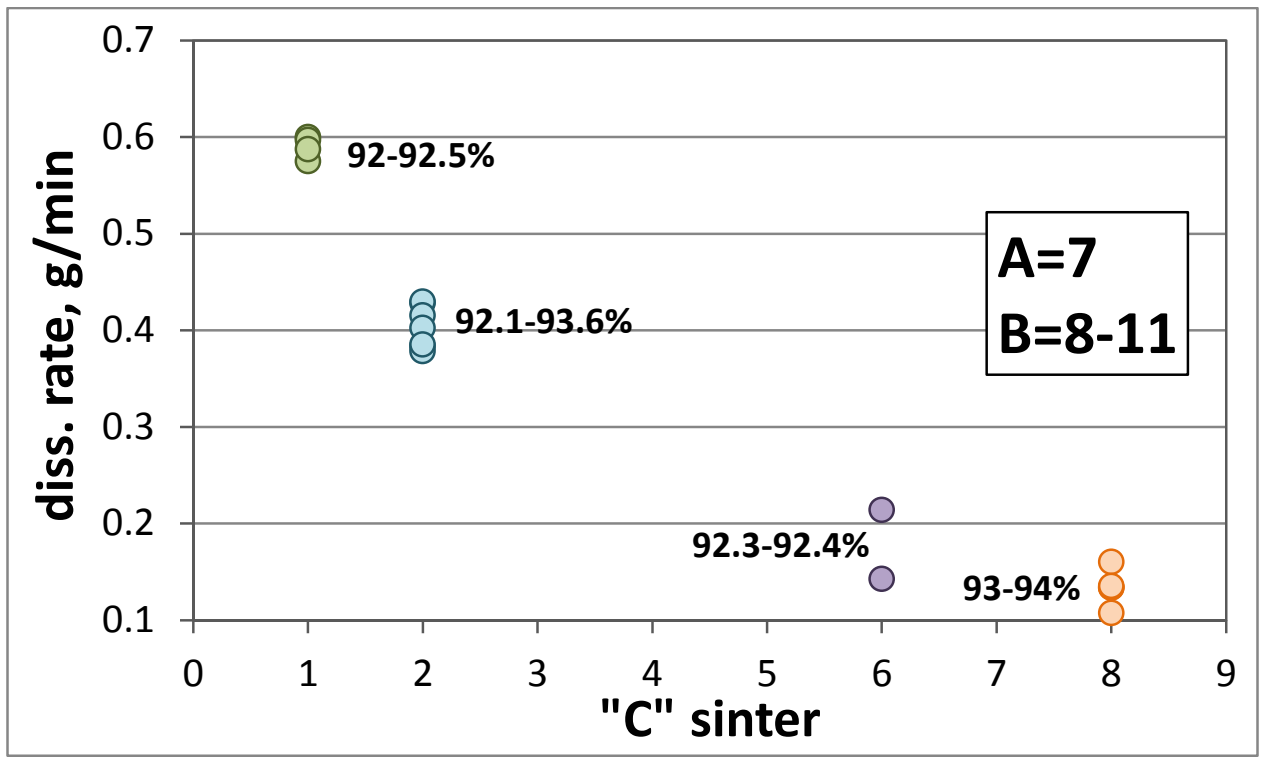

FIGURE 9 Dissolution Rates of Disks Pre-sintered at $\mathrm{A}=7$ and Sintered at Different Conditions with Densities 92-94\%
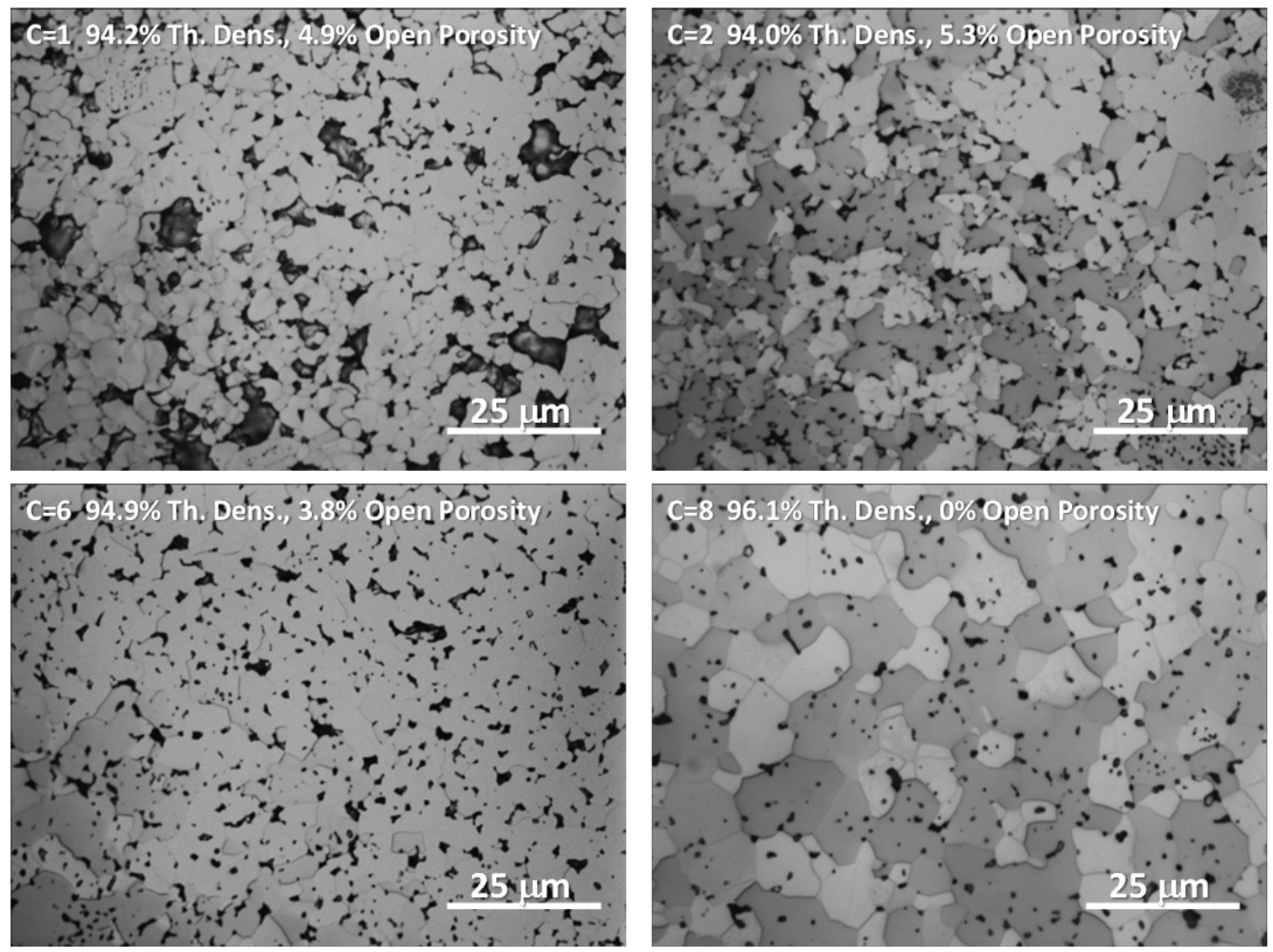

FIGURE 10 Optical Micrographs of Polished Sections of Mo Disks Pre-sintered at A = 7, Pressed at $B=9$, and Sintered at Four Different Conditions $C=1,2,6$, and 8. 
conditions $(\mathrm{C}=2,6$, and 8) had stronger inter-particle bonds and do not show removal of Mo particles. The disk sintered at $\mathrm{C}=8$ clearly shows coalescence of particles and significant grain growth. The voids in this disk are located internally within the grains. On the other hand, the porosities of disks sintered at $\mathrm{C}=1,2$, and 6 are located at the interfaces between the original powder particles. These images show the importance of disk microstructure toward dissolution properties. A decrease of open porosity and an increase in bonding of Mo particles for disks sintered at stronger conditions explain poor dissolution properties.

\subsection{DISSOLUTION OF ORNL SINTERED Mo DISKS}

The first set of disks represented samples prepared from three different starting Mo materials (Table 1). It is clear from the data that non-sintered disks 1 and 5 dissolve very fast. A very good example of how sintering affects the properties of the disk is to compare the dissolution rates of disks 1 and 2. Dissolutions were performed in $\sim 40 \mathrm{~mL}$ of hydrogen peroxide pre-heated to $70^{\circ} \mathrm{C}$.

The green packing density of disk 2 is $80.8 \%$; this increases to $87.2 \%$ by sintering at $1600^{\circ} \mathrm{C}$. A similar trend is apparent for other disks sintered at high temperatures (e.g., disks 3, 4, and 6). However, the dissolution rates between disks 1 and 2 are significantly different despite very similar packing densities, with the non-sintered disk dissolving more than two times faster. The same relationship is observed for disks 5 and 6 . It is also interesting to see a significant difference in dissolution rates for disks 9 and 10. Both disks were prepared from the same material, with the same pressing and sintering conditions. In addition, disk 10 was prepared from coarser Mo powder and treated at a higher temperature, which resulted in a higher dissolution rate, most likely due to significantly higher open porosity and lower packing density.

Another set of disks (disks 11-37) was prepared from six different Mo powders, and several parameters were tested to study packing density and dissolution rates (Table 2). All disks were sintered under $\mathrm{Ar} / 4 \% \mathrm{H}_{2}$ atmosphere. Four different Mo powders were used to make coldpressed disks. The densities were in the range of $89.7-94.3 \%$ and depend mostly on the starting material used and the sintering temperature. Very good dissolution rates were observed for nonsintered samples $(\sim 1 \mathrm{~g} / \mathrm{min})$. However, it should be pointed out that for some materials, including enriched Mo-100 material (discussed later), disks needed to be sintered in order to achieve $>90 \%$ packing density.

Sintered disks (Table 2) were made of three different Mo powders, all pressed at $100 \mathrm{ksi}$ and treated and sintered at different temperatures. Dissolution rates differ significantly for different starting materials. In general, the densities for disks made of CLIMAX EM2 material 'did not exceed $91 \%$ even if sintered at high temperature $\left(1600^{\circ} \mathrm{C}\right)$. A significant difference between CLIMAX NM3 and Atl. Eq. Eng. (AEE) powders is that the disks made of CLIMAX $\mathrm{NM} 3$ sintered at $1400^{\circ} \mathrm{C}$ produced very high density $(>94.5 \%)$, while to make disks with $94 \%$ density from AEE powders, sintering needed to be take place at $1600^{\circ} \mathrm{C}$. The best dissolving sintered disks were disks made of Atl. Eq. Eng. powders. A comparison of dissolution 
TABLE 1 Characteristics of Sintered Mo Disks and Corresponding Dissolution Rates

\begin{tabular}{|c|c|c|c|c|c|c|c|c|c|c|c|c|c|}
\hline \multirow[b]{3}{*}{ Disk } & \multicolumn{2}{|c|}{ Powder } & \multirow{3}{*}{$\begin{array}{c}\text { Press } \\
\text { (ksi) }\end{array}$} & \multirow{3}{*}{$\begin{array}{c}\text { Green } \\
\text { Dens. } \\
(\%)\end{array}$} & \multicolumn{3}{|c|}{ Sintering } & \multirow{3}{*}{$\begin{array}{c}\text { Sinter } \\
\text { Dens } \\
(\%) \\
\end{array}$} & \multirow{3}{*}{$\begin{array}{c}\text { Open } \\
\text { Porosity } \\
(\%)\end{array}$} & \multirow{2}{*}{\multicolumn{2}{|c|}{ Dimensions (mm) }} & \multirow{3}{*}{$\begin{array}{l}\text { Mass } \\
(\mathrm{g})\end{array}$} & \multirow{3}{*}{$\begin{array}{c}\text { Diss. } \\
\text { Rate }^{\mathrm{b}} \\
\text { (g/min) }\end{array}$} \\
\hline & & & & & \multirow{2}{*}{$\begin{array}{c}\text { Temp. } \\
\left({ }^{\circ} \mathrm{C}\right)\end{array}$} & \multirow{2}{*}{$\begin{array}{c}\text { Time } \\
(\mathrm{hr})\end{array}$} & \multirow[b]{2}{*}{ Atm } & & & & & & \\
\hline & Type $^{a}$ & $\left({ }^{\circ} \mathrm{C}\right)$ & & & & & & & & Diameter & Thickness & & \\
\hline 1 & AA & None & 200 & 89.4 & - & - & - & - & 6.3 & 9.57 & 1.16 & 0.75 & $0.69, \mathrm{GS}$ \\
\hline 2 & AA & None & 100 & 80.8 & 1600 & 1 & Vac & 87.2 & 11.4 & 9.25 & 1.29 & 0.74 & 0.32 \\
\hline 3 & AA & None & 100 & 80.5 & 1600 & 1 & Vac & 89 & 4.2 & 12.25 & 2.38 & 2.46 & 0.37 \\
\hline 4 & $\mathrm{AA}$ & None & 100 & 79.5 & 1700 & 1 & Vac & 91.6 & 3.7 & 12.1 & 2.33 & 2.46 & 0.28 \\
\hline 5 & EM2 & None & 200 & 90.9 & - & - & - & - & 8 & 9.57 & 1.15 & 0.75 & $0.69, \mathrm{GS}$ \\
\hline 6 & EM2 & None & 100 & 83 & 1600 & 1 & $\mathrm{Vac}$ & 90.3 & 5.6 & 9.18 & 1.29 & 0.75 & $0.19^{c}$ \\
\hline 7 & NM3 & 60 & 200 & 67.4 & 1200 & 1 & $\begin{array}{c}\mathrm{Ar} / 4 \% \\
\mathrm{H}_{2}\end{array}$ & 90 & 3.2 & 8.63 & 1.1 & 0.58 & 0.33 \\
\hline 8 & NM3 & 800 & 100 & 61.6 & 1100 & 1 & $\begin{array}{c}\mathrm{Ar} / 4 \% \\
\mathrm{H}_{2}\end{array}$ & 87.3 & 11.3 & 8.45 & 1.22 & 0.60 & 0.38 \\
\hline 9 & NM3 & 800 & 200 & 72.8 & 1100 & 1 & $\begin{array}{c}\mathrm{Ar} / 4 \% \\
\mathrm{H}_{2}\end{array}$ & 92.7 & 0.6 & 8.81 & 1.06 & 0.60 & 0.26 \\
\hline 10 & NM3 & 1000 & 200 & 81.1 & 1100 & 1 & $\begin{array}{c}\mathrm{Ar} / 4 \% \\
\mathrm{H}_{2}\end{array}$ & 86.2 & 13.9 & 9.37 & 1.02 & 0.60 & 0.60 \\
\hline
\end{tabular}

a $\quad$ AA = Alfa Aesar; EM2 = Climax Em2; NM3 = Climax NM3.

b $\quad \mathrm{GS}=$ green solution formed.

c Additional heating applied.

rates versus packing density for non-sintered and sintered disks made of different starting material is shown in Figure 11.

It is clear that dissolution rates are very sensitive to sintering temperature, but the starting material can also affect properties of the disks. Figure 12 shows SEM images of two Climax Mo powders in the as-received, as-pressed, and sintered conditions. After sintering, the powder particles have coalesced to form large grains that are joined to each other with diffusion bonds. The remaining porosity becomes trapped within the grains, and, therefore, the dissolution rates are very low. The effect of sintering temperature on disk properties, which significantly affect the density and dissolution rates, is shown in Figures 13 and 14.

Data in Figure 14 show the importance of powder treatment before pressing and sintering the disks. The negative effect of sintering temperature on dissolution rates is clearly visible; however, increasing the temperature of powder treatment before pressing in general has a positive effect on dissolution rates. From the data presented, it is clear that sintering temperature affects the dissolution rates due to a change in the microstructure of the Mo powder. However, increased packing density may play an important role as well. The effect of packing density on dissolution rates can be seen for non-sintered disks pressed at different conditions in Figure 15. 
TABLE 2 Characteristics of Sintered Mo Disks and Corresponding Dissolution Rates

\begin{tabular}{|c|c|c|c|c|c|c|c|c|c|c|c|c|}
\hline \multirow[b]{3}{*}{ Disk } & \multirow{2}{*}{\multicolumn{2}{|c|}{ Powder }} & \multirow{3}{*}{$\begin{array}{c}\text { Press. } \\
\text { (ksi) }\end{array}$} & \multirow{3}{*}{$\begin{array}{c}\text { Green } \\
\text { Dens. } \\
(\%) \\
\end{array}$} & \multicolumn{2}{|c|}{ Sintering } & \multirow{3}{*}{$\begin{array}{c}\text { Sinter } \\
\text { Dens. } \\
(\%) \\
\end{array}$} & \multirow{3}{*}{$\begin{array}{c}\text { Open } \\
\text { Porosity } \\
(\%)\end{array}$} & \multirow{2}{*}{\multicolumn{2}{|c|}{ Dimensions (mm) }} & \multirow{3}{*}{$\begin{array}{c}\text { Mass } \\
(\mathrm{g})\end{array}$} & \multirow{3}{*}{$\begin{array}{c}\text { Diss. } \\
\text { Rate }^{\mathrm{b}} \\
(\mathrm{g} / \mathrm{min}) \\
\end{array}$} \\
\hline & & & & & \multirow{2}{*}{$\begin{array}{c}\text { Temp. } \\
\left({ }^{\circ} \mathrm{C}\right)\end{array}$} & \multirow{2}{*}{$\begin{array}{l}\text { Time } \\
(\mathrm{hr})\end{array}$} & & & & & & \\
\hline & Type $^{\mathrm{a}}$ & Treat. & & & & & & & Diameter & Thickness & & \\
\hline 11 & $\mathrm{AA}$ & None & 200 & 89.7 & - & - & - & 6.5 & 12.75 & 0.996 & 1.14 & $1.14, \mathrm{GS}$ \\
\hline 12 & EM2 & None & 200 & 91.0 & - & - & - & 8.3 & 12.75 & 0.989 & 1.15 & $1.15, \mathrm{GS}$ \\
\hline 13 & EM2 & None & 250 & 92.9 & - & - & - & 5.7 & 12.76 & 0.955 & 1.15 & $1.09, \mathrm{GS}$ \\
\hline 14 & HDFM & None & 200 & 90.8 & - & - & - & 8.1 & 12.75 & 0.986 & 1.14 & $1.52, \mathrm{GS}$ \\
\hline 15 & NPA & None & 200 & 91.9 & - & - & - & 7.4 & 12.75 & 0.972 & 1.15 & $1.08, \mathrm{GS}$ \\
\hline 16 & NPA & None & 250 & 94.3 & - & - & - & 5.1 & 12.75 & 0.944 & 1.15 & $0.93, \mathrm{GS}$ \\
\hline 17 & AEE & $800^{\circ} \mathrm{C}$ & 100 & 77.6 & 1400 & 1 & 89.7 & 7.1 & 12.13 & 1.10 & 1.14 & 0.62 \\
\hline 18 & AEE & None & 100 & 77.4 & 1500 & 1 & 91.7 & 0.3 & 11.95 & 1.12 & 1.15 & 0.38 \\
\hline 19 & AEE & $800^{\circ} \mathrm{C}$ & 100 & 77.6 & 1500 & 1 & 91.9 & 0.2 & 11.97 & 1.12 & 1.14 & 0.36 \\
\hline 20 & AEE & $1000^{\circ} \mathrm{C}$ & 100 & 77.8 & 1500 & 1 & 92.0 & 0.5 & 11.98 & 1.11 & 1.15 & 0.41 \\
\hline 21 & AEE & $1100^{\circ} \mathrm{C}$ & 100 & 77.5 & 1500 & 1 & 91.5 & 4.4 & 11.96 & 1.11 & 1.15 & 0.38 \\
\hline 22 & AEE & None & 100 & 77.4 & 1600 & 1 & 93.8 & 0.1 & 11.87 & 1.12 & 1.15 & $0.18^{\mathrm{c}}$ \\
\hline 23 & AEE & $800^{\circ} \mathrm{C}$ & 100 & 77.6 & 1600 & 1 & 94.0 & 0.0 & 11.86 & 1.10 & 1.14 & $0.19^{c}$ \\
\hline 24 & AEE & $1000^{\circ} \mathrm{C}$ & 100 & 77.8 & 1600 & 1 & 94.3 & 0.0 & 11.85 & 1.10 & 1.15 & $0.2^{\mathrm{c}}$ \\
\hline 25 & AEE & $1100^{\circ} \mathrm{C}$ & 100 & 77.5 & 1600 & 1 & 93.9 & 0.0 & 11.89 & 1.09 & 1.15 & $0.21^{\mathrm{c}}$ \\
\hline 26 & EM2 & None & 100 & 81.3 & 1500 & 1 & 89.7 & 8.8 & 12.28 & 1.09 & 1.15 & $0.27^{\mathrm{c}}$ \\
\hline 27 & EM2 & $1000^{\circ} \mathrm{C}$ & 100 & 81.0 & 1500 & 1 & 89.5 & 7.2 & 12.28 & 1.09 & 1.15 & $0.27^{\mathrm{c}}$ \\
\hline 28 & EM2 & None & 100 & 81.3 & 1600 & 1 & 90.5 & 0.1 & 12.20 & 1.09 & 1.15 & $0.18^{\mathrm{c}}$ \\
\hline 29 & EM2 & $800^{\circ} \mathrm{C}$ & 100 & 81.0 & 1600 & 1 & 89.5 & 2.9 & 12.24 & 1.10 & 1.16 & $0.21^{\mathrm{c}}$ \\
\hline 30 & EM2 & $1000^{\circ} \mathrm{C}$ & 100 & 81.0 & 1600 & 1 & 90.4 & 0.4 & 12.21 & 1.09 & 1.15 & $0.19^{c}$ \\
\hline 31 & EM2 & $1100^{\circ} \mathrm{C}$ & 100 & 80.1 & 1600 & 1 & 89.5 & 5.1 & 12.18 & 1.10 & 1.15 & $0.2^{\mathrm{c}}$ \\
\hline 32 & NM3 & $800^{\circ} \mathrm{C}$ & 100 & 59.3 & 1300 & 1 & 90.1 & 2.6 & 10.95 & 1.35 & 1.15 & 0.36 \\
\hline 33 & NM3 & $900^{\circ} \mathrm{C}$ & 100 & 62.0 & 1300 & 1 & 90.6 & 3.7 & 11.10 & 1.33 & 1.15 & 0.41 \\
\hline 34 & NM3 & $1000^{\circ} \mathrm{C}$ & 100 & 65.4 & 1300 & 1 & 89.5 & 8.1 & 11.32 & 1.30 & 1.15 & 0.46 \\
\hline 35 & NM3 & $800^{\circ} \mathrm{C}$ & 100 & 59.3 & 1400 & 1 & 94.6 & 2.7 & 10.71 & 1.35 & 1.13 & $0.1^{\mathrm{c}}$ \\
\hline 36 & NM3 & $900^{\circ} \mathrm{C}$ & 100 & 62.0 & 1400 & 1 & 95.4 & 1.9 & 10.85 & 1.32 & 1.12 & $0.12^{\mathrm{c}}$ \\
\hline 37 & NM3 & $1000^{\circ} \mathrm{C}$ & 100 & 65.4 & 1400 & 1 & 96.5 & 0.8 & 11.02 & 1.28 & 1.15 & $0.12^{\mathrm{c}}$ \\
\hline
\end{tabular}

a $\quad \mathrm{AA}=$ Alfa Aesar; AEE = Atl. Equip. Eng.; EM2 = Climax Em2; NM3 = Climax NM3; NPA = Climax NPA.

b $\mathrm{GS}=$ green solution formed.

c Additional heating applied.

Although the dissolution rates observed for non-sintered disks are very high for all packing densities in the range of $91.5-95.3 \%$, there is a noticeable effect of packing density on dissolution rate. The increase of $3.4 \%$ in packing density reduces the dissolution rate by $20 \%$. This trend could be even stronger for sintered disks.

Table 3 shows the characteristics for sintered disks made from IsoFlex $>99 \%$ enriched Mo-100 powder. Surprisingly, despite relatively high open porosity and low sintering temperature, the dissolution rates for all Mo-100 enriched disks were relatively low, and additional heating was required for complete dissolution; this could be due to smaller surface area. However, it should be noted that the dissolution was very slow only at the beginning, when the temperature of the $\mathrm{H}_{2} \mathrm{O}_{2}$ was $70^{\circ} \mathrm{C}$; once the temperature of $\mathrm{H}_{2} \mathrm{O}_{2}$ was increased to $\sim 95-100^{\circ} \mathrm{C}$ by additional heating, the dissolution started to progress very quickly, with complete dissolution occurring in 1-1.5 min. This is very promising, because actual irradiated Mo targets 
will be dissolved at higher temperatures, which could lead to significantly shorter dissolution times. At the same time, the dissolution data for Mo-100 enriched disks demonstrate the importance of starting material on the characteristics of the final disks. Future studies should therefore focus on the preparation of disks from powder that was obtained by reduction of $\mathrm{MoO}_{3}$ powder. This is important because after recovering spent Mo-99 source solution from the generator, enriched Mo-100 material needs to be recovered and purified from potassium molybdate solution and recycled by conversion to $\mathrm{MoO}_{3}$ that can be reduced to Mo powder and used for production of new disks. Therefore, it is important to understand that the dissolution of sintered Mo disks and the recovery of Mo-100 are directly interconnected, since one produces a starting material for the other.

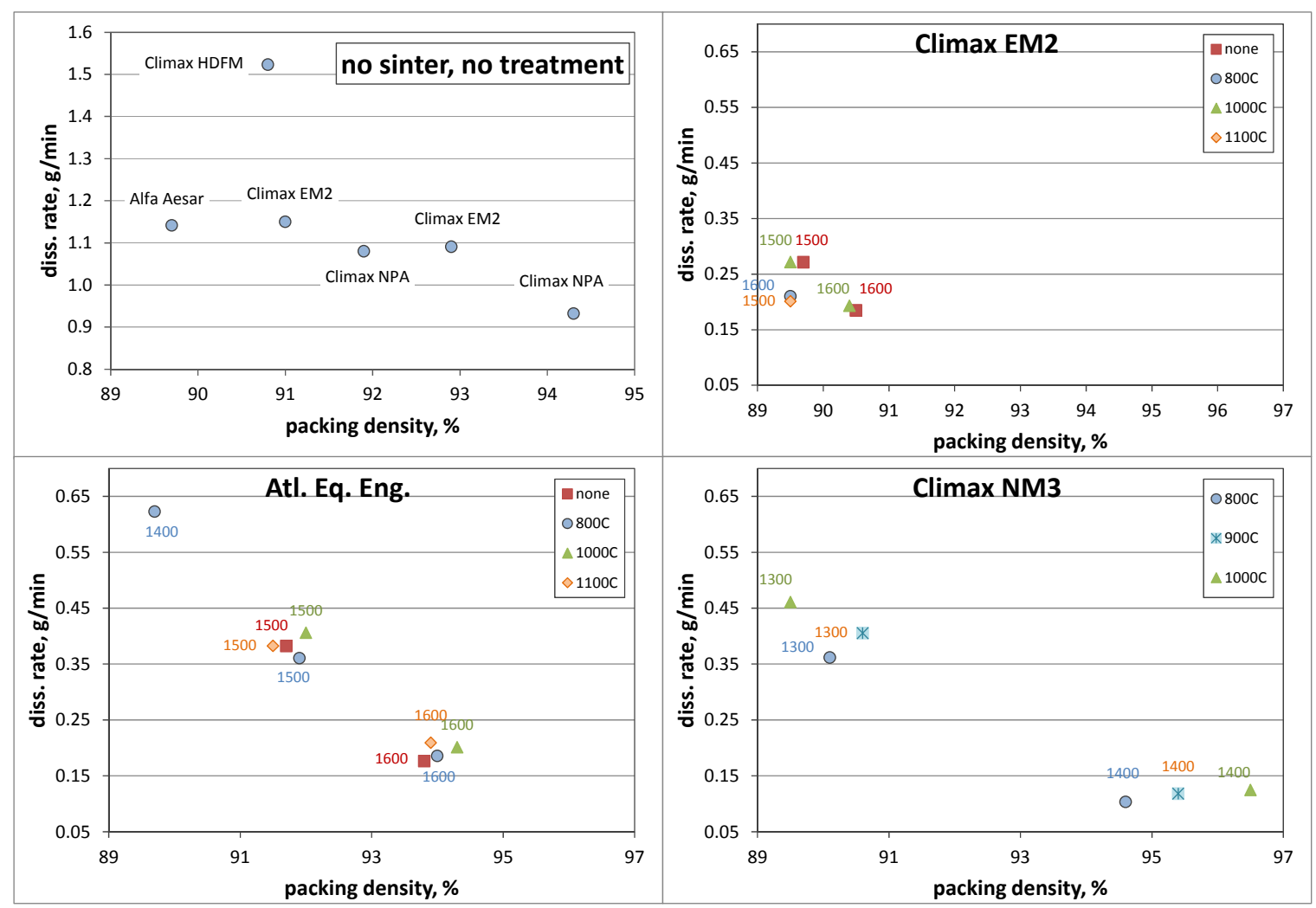

FIGURE 11 Comparison of Dissolution Rates Versus Packing Density for Non-sintered and Sintered Disks Made of Different Starting Material (Data points for sintered disks indicate temperature of sintering.) 

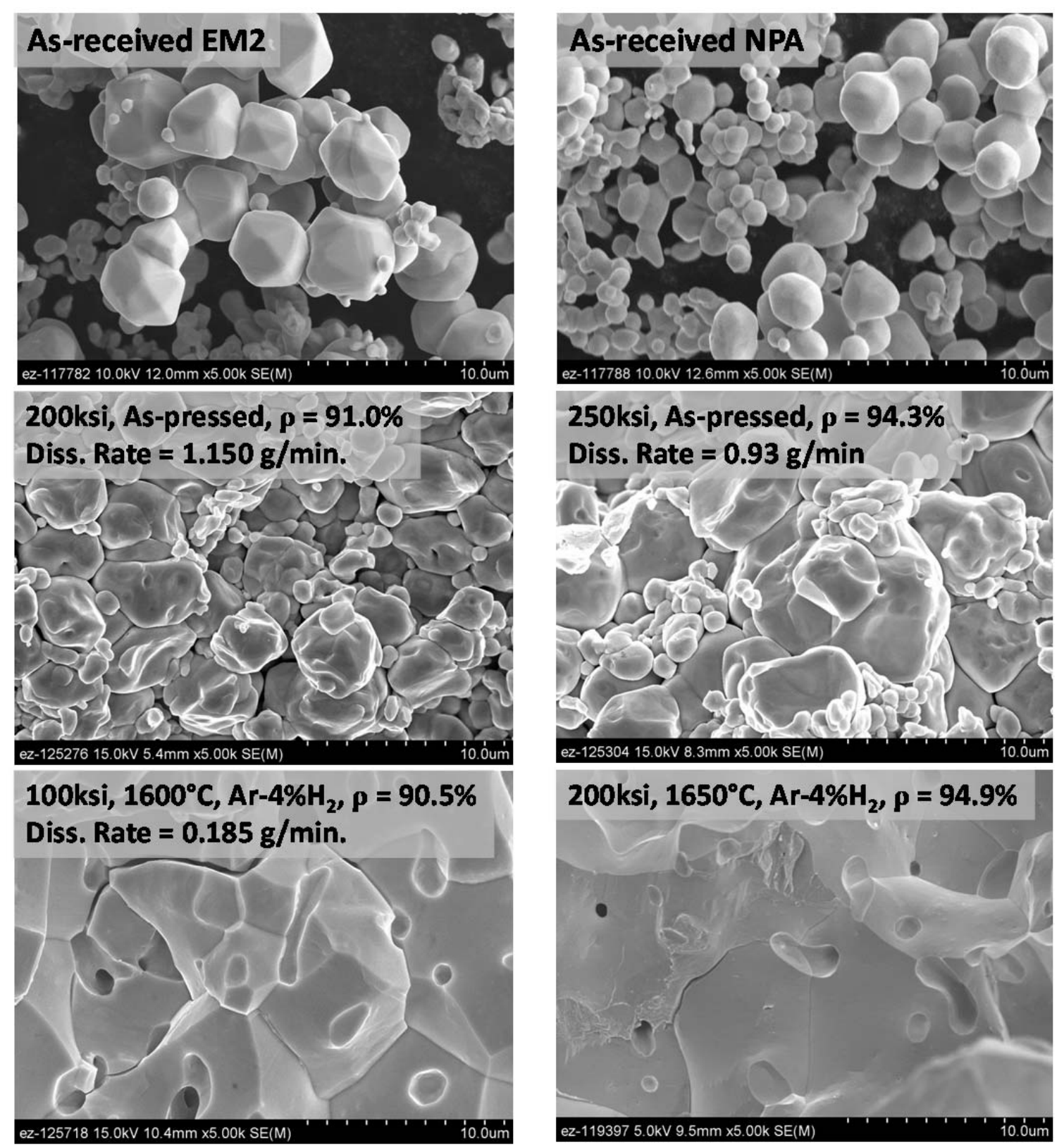

FIGURE 12 SEM Images of Two Climax Mo Powders As-Received (Top), and Fracture Surfaces of As-Pressed (Middle) and Sintered (Bottom) Disks 


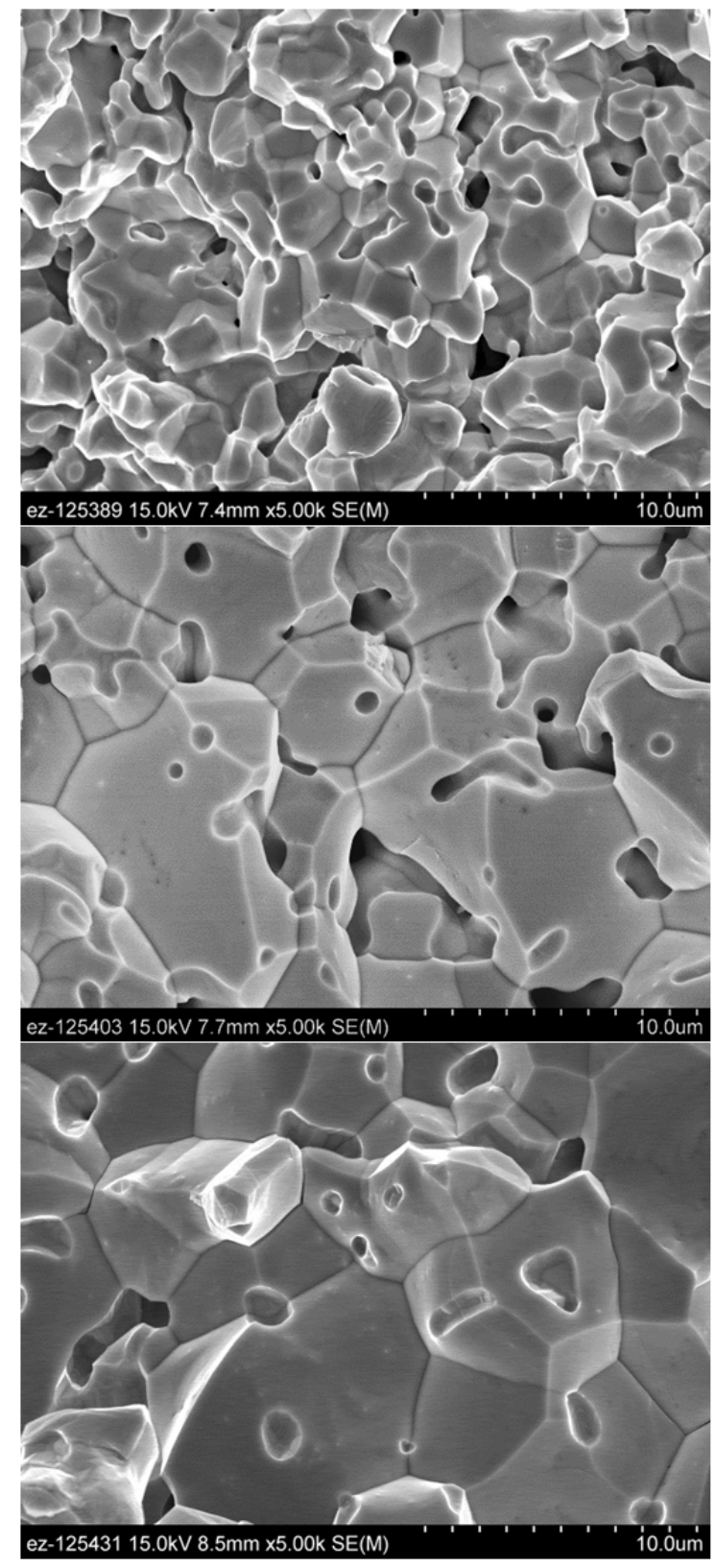

$1400^{\circ} \mathrm{C}$

Density $=89.7 \%$

Open Porosity $=7.1 \%$

Diss. Rate $=0.623 \mathrm{~g} / \mathrm{min}$

$1500^{\circ} \mathrm{C}$

Density $=\mathbf{9 1 . 9 \%}$

Open Porosity $=0.2 \%$

Diss. Rate $=0.361 \mathrm{~g} / \mathrm{min}$

$1600^{\circ} \mathrm{C}$

Density $=\mathbf{9 4 . 0} \%$

Open Porosity = 0\%

Diss. Rate $=0.186 \mathrm{~g} / \mathrm{min}$

FIGURE 13 SEM Images of Fracture Surfaces of Sintered AEE Mo Disks Show the Effect of Sintering Temperatures on the Microstructure (As the temperature increases, grain size and diffusion bonding increase while the open porosity and dissolution rates decrease.) 


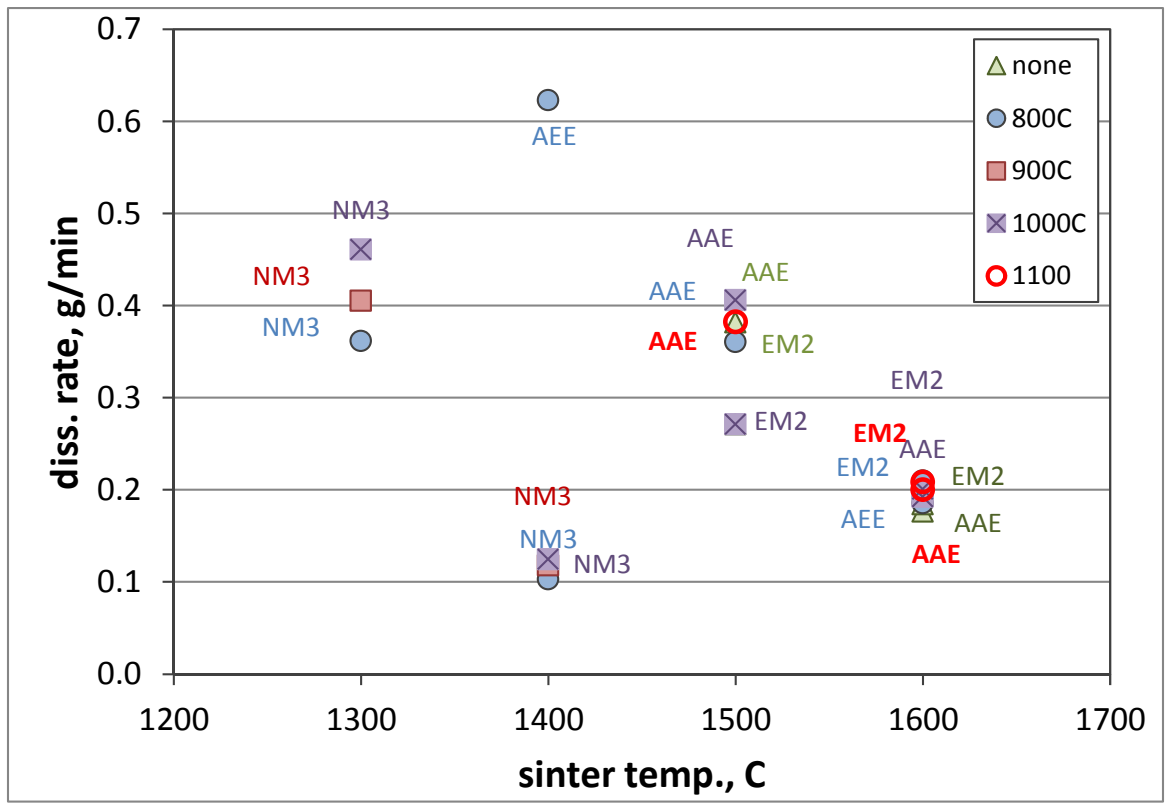

FIGURE 14 Comparison of Dissolution Rates Versus Sintering Temperature for Different Mo powders Pretreated at Different Conditions (EM2 = Climax EM2; AEE = Atl. Equip. Eng.; NM3 = Climax NM3)

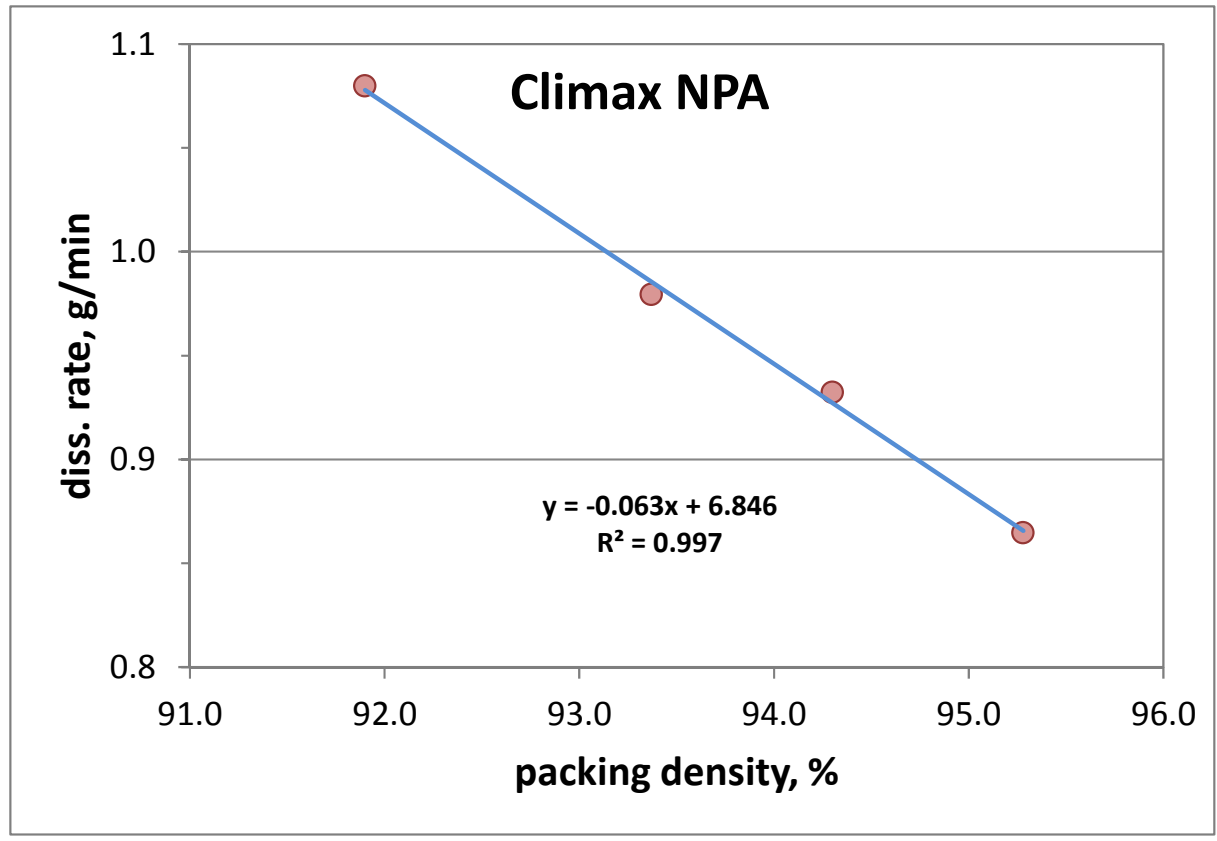

FIGURE 15 Dependence of Dissolution Rates of Non-sintered Mo Disks on Packing Density 
TABLE 3 Characteristics of Sintered $>99 \%$ Mo-100 Enriched Disks and Corresponding Dissolution Rates

\begin{tabular}{|c|c|c|c|c|c|c|c|c|c|c|c|c|}
\hline \multirow[b]{3}{*}{ Disk } & & & & & \multicolumn{2}{|c|}{ Sintering } & \multirow{3}{*}{$\begin{array}{c}\text { Sinter } \\
\text { Dens. } \\
(\%)\end{array}$} & \multirow{3}{*}{$\begin{array}{c}\text { Open } \\
\text { Porosity } \\
(\%)\end{array}$} & \multirow{2}{*}{\multicolumn{2}{|c|}{ Dimensions (mm) }} & \multirow[b]{3}{*}{$\begin{array}{l}\text { Mass } \\
(\mathrm{g})\end{array}$} & \multirow[b]{3}{*}{$\begin{array}{c}\text { Diss. Rate } \\
(\mathrm{g} / \mathrm{min})\end{array}$} \\
\hline & \multicolumn{2}{|c|}{ Powder } & \multirow[b]{2}{*}{$\begin{array}{c}\text { Press. } \\
\text { (ksi) }\end{array}$} & \multirow{2}{*}{$\begin{array}{c}\text { Green } \\
\text { Dens. } \\
(\%)\end{array}$} & \multirow[b]{2}{*}{$\begin{array}{l}\text { Temp } \\
\left({ }^{\circ} \mathrm{C}\right)\end{array}$} & \multirow[b]{2}{*}{$\begin{array}{c}\text { Time } \\
(\mathrm{hr})\end{array}$} & & & & & & \\
\hline & Type $^{\mathrm{a}}$ & Treat. & & & & & & & Diameter & Thickness & & \\
\hline 43 & IF 4663 & None & 100 & 69.2 & 1200 & 1 & 91.7 & 3.3 & 8.56 & 1.11 & 0.5849 & $0.10^{\mathrm{b}}$ \\
\hline 44 & IF 4178 & None & 100 & 65.1 & 1300 & 1 & 89.8 & 1.5 & 8.68 & 1.05 & 0.5915 & $0.14^{\mathrm{b}}$ \\
\hline 45 & IF 4663 & None & 200 & 81.6 & 1000 & 1 & 89.7 & 8.4 & 9.25 & 0.89 & 0.5575 & $0.22^{\mathrm{b}}$ \\
\hline 46 & IF 4663 & 1000 & 200 & 84.4 & 1000 & 1 & 89.5 & 9.5 & 9.43 & 1.03 & 0.6446 & $0.25^{\mathrm{b}}$ \\
\hline
\end{tabular}

a $\quad$ IF $=$ IsoFlex $99+\%$ Mo-100 enriched Mo powder.

b Additional heating applied. 


\section{SUMMARY}

Dissolution studies performed on NorthStar and ORNL disks show that an increase in sintering temperature has a negative effect on dissolution rates in $30 \%$ hydrogen peroxide. This is due to changes in the microstructure of sintered Mo powder. At higher sintering temperatures, the powder particles coalesce, form diffusion bonds, and grow into larger grains, which reduce the open porosity of the disks. The remaining porosity becomes trapped within the grains, and therefore the dissolution rates are very low. We also observed that different starting materials lead to different dissolution properties, and in some cases, even high sintering temperature at $1600^{\circ} \mathrm{C}$ does not produce disks with high packing densities. Studies with NorthStar disks showed that increased packing density can be achieved by increased pressing conditions without affecting the dissolution rates if mild sintering conditions are used.

Future experiments will focus on producing sintered Mo disks produced from recovered Mo material and on optimizing the sintering process to produce disks with $>90 \%$ packing density and good dissolution rates. 


\section{REFERENCE}

Tkac, P., G.F. Vandegrift, and J. Harvey, Dissolution of Sintered Mo Disks, ANL/CSE-13/19, Argonne National Laboratory, July 2012. 



\section{Argonne}

Chemical Science and Engineering Division

Argonne National Laboratory

9700 South Cass Avenue, Bldg. 205

Argonne, IL 60439-4837

www.anl.gov 